\title{
Be and $W$ in Neutral Mine Drainage and the impact on Silican Algaes
}

\author{
LINA P.B. HÄLLSTRÖM ${ }^{1}$, LENA ALAKANGAS ${ }^{1}$
}

'Applied Geochemistry, LTU, Sweden Lina.hallstrom@ltu.se

The geochemical behavior of $\mathrm{Be}$ and $\mathrm{W}$ in the terrestrial environment are poorly studied even though both are potentially harmful elements.

In Yxsjöberg, Sweden, skarn tailings containing $\mathrm{Be}$ and $\mathrm{W}$ together with Fe-sulfides, carbonates and fluorite have been stored uncovered for more than $50 \mathrm{y}$. Chemical analysis of the mine drainage enables a comparison and understanding of the geochemical behavior of $\mathrm{Be}$ and $\mathrm{W}$. The presence and deformation of silican algaes from the river-bed was used as bioindicators of the ecosystem.

Oxidation of the unusual mineral danalite in the tailings had released the highest Be-concentrations worldwide to the groundwater $(4.5 \mathrm{mg} / \mathrm{L})$ and severely high concentrations to the surface water. Beryllium in circumneutral mine drainage were strongly correlated with $\mathrm{F}\left(\mathrm{R}^{2}=0.95\right)$. In the tailings, carbonates released from calcite due to neutralization of sulfide oxidation had exchanged with $\mathrm{WO}_{4}$ at the surfaces of scheelite and mobilized W. Most W was retained in the tailings by adsorption to hydrous ferric oxides, and therefore, $\mathrm{W}$-concentrations in ground and surface water were low. Downstream the repository, the present species of Silican Algaes and their deformation indicated a potentially harmful environment compared to a reference sample. This was probably due to the low $\mathrm{pH}$ and the high concentrations of $\mathrm{Be}$ and $\mathrm{F}$.

A negative impact on silican algaes was also detected downstream a newer covered repository of Yxsjöberg, where the river water had a neutral $\mathrm{pH}$ (6.7) and solely high concentrations of dissolved $\mathrm{W}$.

Both the Be-F-complexes from the old uncovered tailings and diss.W from the new covered tailings were transported $>5 \mathrm{~km}$ from the mine site. 